\title{
A NECESSIDADE DE PARÂMETROS PARA A EFETIVAÇÃO DO DIREITO À SAÚDE: A JUDICIALIZAÇÃO DO ACESSO AO HORMÔNIO DO CRESCIMENTO NO ESTADO DO PARÁ
}

The necessity of parameters for effectuation of right to health: judicial action for access to growth hormone in the State of Pará

${ }^{1}$ Centro Universitário do Pará. Belém/PA, Brasil.

Correspondência: Loiane Prado Verbicaro. E-mail: loianeverbicaro@uol.com.br. 


\section{RESUMO}

O presente trabalho é resultado de pesquisa acerca da aquisição do medicamento somatropina, o hormônio do crescimento, pela Secretaria de Saúde Pública do Estado do Pará no período que compreende os anos de 2009 a 2013. O estudo teve como objetivo analisar os efeitos da judicialização do acesso ao medicamento com base na medida liminar exarada, nos autos da Ação Civil Pública n. 0021681-17.2011.8.14.0301, que determinou ao Estado do Pará o fornecimento do medicamento Hormotrop ${ }^{\circledR}$ - Somatropina 12 UI para todas as crianças e adolescentes com deficiência na produção de hormônio do crescimento, e demonstrar, através de um caso concreto, a necessidade de estabelecer parâmetros que possam subsidiar o Poder Judiciário na análise das ações que visam a efetivar o direito à saúde. Foi realizada pesquisa bibliográfica sobre os aspectos jurídicos que envolvem o processo de judicialização da saúde, bem como sobre os aspectos técnicos e psicológicos atinentes ao uso do hormônio do crescimento e acerca das políticas públicas relacionadas a seu acesso. Os dados coletados demonstraram que houve mudança no padrão de consumo do medicamento somatropina a partir do ano de 2011 - mesmo período em que foi proferida a decisão liminar na referida ACP. Tal conclusão suscita a necessidade de estabelecer parâmetros baseados em critérios técnicos na análise das ações que envolvem questões relacionadas a medicamentos, em um contexto de crescente judicialização da política e das relações sociais no Brasil.

\section{Palavras-Chave}

Direito à Saúde; Estado do Pará; Judicialização da Saúde; Políticas Públicas.

\section{ABSTRACT}

This work is the result of research on the acquisition of the medication Somatropin, the growth hormone, by the Public Health Department of the State of Pará, during the years 2009 to 2013. The study aimed to analyze the effects of court action for access to medication based on the preliminary injunction, in the records of the Public Civil Action (GPA) $\mathrm{n}^{\circ}$ 0021681-17.2011.8.14.0301, which determined that the State of Pará could supply the drug Hormotrop ${ }^{\circledR}$ - Somatropin $12 \mathrm{IU}$ to all children and adolescents who have a deficiency in the production of growth hormone, and which demonstrated, through a concrete case, the need to establish parameters for judicial action in ensuring the right to health. A review of the literature was undertaken regarding legal aspects involved in the process of legalization of health, the technical and psychological aspects related to the use of growth hormone, and the public policies related to access. The data collected showed that there was a change in the consumption pattern of Somatropin starting from the year 2011, the periodthe above-mentioned civil action injunction was issued, creating the need to establish parameters based on technical criteria for judicial action for issues related to medications, in a context of increasing court action in politics and social relations in Brazil.

\section{Keywords}

Brazilian State of Para; Legalization of Health; Public Policy; Right to Health. 
EMENTA: PROCESSUAL CIVIL. DIREITO CONSTITUCIONAL. APELAÇÃO CÍVEL - AÇÃO CIVIL PÚBLICA COM PEDIDO DE ANTECIPAÇÃO DE TUTELA - DIAGNÓSTICO - FORNECIMENTO IMEDIATO DE MEDICAMENTO HORMOTROP 12 UI, PARA CRIANÇAS E ADOLESCENTES PORTADORES DE DEFICIÊNCIA NA PRODUÇÃO DO HORMÔNIO DO CRESCIMENTO. DIREITO À SAÚDE - DIGNIDADE DA PESSOA HUMANA. FORNECIMENTO PELO ESTADO DO PARÁ - RESPONSABILIDADE SOLIDÁRIA. PRELIMINARES: 1) Ilegitimidade Passiva do Estado, aduzindo responsável direto o Município de Belém, para promover a entrega do medicamento. Rejeitada. 2) impossibilidade em exigir que o Estado forneça medicamentos para patologias que não estejam na lista do Ministério da Saúde. Rejeitada. 3) da violação ao princípio da reserva do possível diante da escassez de recursos. Rejeição/impossibilidade. 4) do cumprimento da decisão proferida pelo juízo e o pedido de o afastamento da penalidade de multa. Preliminar rejeitada. MÉRITO. DIREITO À SAÚDE E À VIDA. MULTA RAZOÁVEL. SENTENÇA MANTIDA. RECURSO CONHECIDO E DESPROVIDO. DECISÃO UNÂNIME. I- Na área da saúde devem ser observadas as circunstâncias específicas de cada caso concreto, considerando que tais orientações viabilizam a própria prestação do direito em referência. Não se pode olvidar que em determinadas situações específicas, a estrita observância destes regulamentos poderá implicar em prejuízo grave à saúde da parte e, em ofensa à garantia do art. 196 da Constituição. II- Em se tratando de medicamento de alto custo, o Estado do Pará tem o dever de fornecê-lo, não sendo razoável impor a qualquer outro Órgão a dispensação de medicamento excepcional, já que as políticas públicas conferiram ao Ente Estatal a responsabilidade pela atenção básica na área da saúde, em respeito às características estruturais e orçamentárias. III- Considere-se que a saúde e a vida são direitos garantidos constitucionalmente e que, aos entes federativos é dado o cumprimento do dever capaz de garantir a dignidade e o desenvolvimento saudável e digno das CRIANÇAS E ADOLESCENTES PORTADORES DE DEFICIÊNCIA NA PRODUÇÃO DO HORMÔNIO DO CRESCIMENTO. IV- Recurso Conhecido e Desprovido. Decisão Unânime. (TRIBUNAL DE JUSTIÇA DO ESTADO DO PARÁ, TERCEIRA CÂMARA CÍVEL ISOLADA, APELAÇÃO 0021681-17.2011.8.14.030, RELATORA: EDINÉA OLIVEIRA TAVARES)

\section{Introdução}

A definição de saúde, enquanto bem, depende profundamente das representações sociais sobre o significado do estado de saúde, que inevitavelmente refletem a conjuntura social, econômica, política e cultural de uma sociedade ${ }^{1}$.

${ }^{1}$ SCLIAR, Moacyr. História do conceito de saúde. Disponível em: <http://www.scielo.br/pdf/physis/v17n1/ v17n1a03.pdf>. Acesso em: 03 fev. 2015. 
A mais conhecida definição de saúde é aquela da Organização Mundial da Saúde (OMS), idealizada a partir da Conferência Internacional de Saúde de 22 de julho de 1946, em Nova Iorque. Segundo a OMS, saúde é um estado de completo bem-estar físico, mental e social, não consistindo somente em ausência de enfermidade ${ }^{2}$.

No âmbito jurídico, o direito à saúde é classificado como um direito social e reconhecido pela comunidade internacional através da Declaração Universal dos Direitos Humanos de 19483 , sendo seus princípios incorporados pelo Brasil na Constituição Federal de $1988(\mathrm{CF} / 88)^{4}$.

$\mathrm{Na} \mathrm{CF} / 88$ estão institucionalizados os direitos humanos no País, consagrados em direitos fundamentais, sociais e econômicos, de aplicação imediata. E, entre esses direitos, encontra-se o direito à saúde, expresso no artigo $6^{\circ}$ como um direito social ${ }^{5}$.

No artigo 196, a CF/88 prevê a saúde como direito de todos e dever do Estado, garantido mediante políticas públicas sociais e econômicas que visem à redução do risco de doença e outros agravos e ao acesso universal e igualitário às ações e serviços para sua promoção, proteção e recuperação.

No plano infraconstitucional, a Lei Federal n. 8.080/1990 (Lei Orgânica da Saúde), alçou a saúde ao nível de "um direito fundamental do ser humano, devendo o Estado prover as condições indispensáveis do seu pleno exercício ${ }^{6 "}$ (artigo $2^{\circ}$ ) - disposição legal que deve ser interpretada à luz da Constituição, que garante o direito à saúde mediante políticas sociais e econômicas, as quais devem visualizar a saúde em sua integralidade desde sua promoção e proteção até sua recuperação ${ }^{7}$.

No artigo $6^{\circ}$ da referida lei ${ }^{8}$ são especificadas ações que dizem respeito aos campos de atuação do Sistema Único de Saúde (SUS), dentre as quais pode-se citar - no inciso I, alínea "d" - a assistência terapêutica integral, inclusive farmacêutica.

\footnotetext{
${ }^{2}$ MILAGRES, Marcelo de Oliveira. Saúde: direito, dever ou valor? Revista CEJ, Brasília, n. 50, p. 25-29, jul./set. 2010. Disponível em: <www.cjf.jus.br/ojs2/index.php/revcej/article/viewArticle/1392>.

${ }^{3}$ UNESCO. Declaração Universal dos Direitos Humanos. Brasília, 1988. Disponível em: <http://unesdoc. unesco.org/images/0013/001394/139423por.pdf>. Acesso em: 31 jan. 2017.

${ }^{4}$ BRASIL. Constituição da República Federativa do Brasil de 1988. Disponível em: <http://www.planalto.gov. br/ccivil_03/constituicao/constituicaocompilado.htm>. Acesso em: 31 jan. 2017.

${ }^{5}$ BRASIL. Conselho Nacional de Secretários da Saúde. Direito à saúde: coleção para entender a gestão do SUS. Brasília: Conass, 2015. p. 15.

"Art. $2^{\circ}$ A saúde é um direito fundamental do ser humano, devendo o Estado prover as condições indispensáveis ao seu pleno exercício." BRASIL. Lei n. 8.080, de 19 de setembro de 1990. Dispõe sobre as condições para a promoção, proteção e recuperação da saúde, a organização e o funcionamento dos serviços correspondentes e dá outras providências. Disponível em: < http://www.planalto.gov.br/ccivil_03/ leis/L8080.htm>. Acesso em: 31 jan. 2017.

${ }^{7}$ BLIACHERIENE, Ana Carla et al. Acesso aos bens de saúde do SUS pela via Judicial. Interesse Público, Belo Horizonte, n. 70, p. 127, nov./dez. 2011.

${ }^{8}$ BRASIL. Lei n. 8.080, de 19 de setembro de 1990, cit.
} 
O medicamento é uma das tecnologias mais utilizadas pelo setor de saúde e considerado essencial para a prática da medicina ocidental, sendo o acesso a ele pedra angular na Política Nacional de Medicamentos ${ }^{9}$.

A assistência farmacêutica no SUS é um debate que vem sendo travado nos sistemas sanitário e de justiça, visto que a chamada judicialização da saúde inicia-se nos idos dos anos 1990, com pedidos de medicamentos para tratamento da Síndrome de Imunodeficiência Adquirida (AIDS), e segue até os anos 2005. Esse panorama já foi alterado, todavia os medicamentos ainda são um importante objeto das ações judiciais ${ }^{10}$.

Passados mais de 20 anos das primeiras incursões no Judiciário que visavam a garantir aos portadores de HIV o acesso aos medicamentos e demais insumos necessários, o que se pode observar hoje, a partir de uma análise da jurisprudência dos tribunais de todo o país, é que o direito à saúde tem sido encarado como um direito ilimitado, que implica o fornecimento de todo e qualquer medicamento ${ }^{11}$.

No contexto da realidade do Estado do Pará, objeto de estudo do presente artigo, segundo relatório conclusivo de pesquisa sobre a judicialização da saúde pública no estado no período de 2007 a 2012, promovida pelo Centro Universitário do Pará, há uma crescente judicialização das demandas de saúde. O estudo quantitativo e qualitativo de decisões judiciais sobre saúde no Pará concluiu que a saúde pública no Estado encontra-se a cada ano mais judicializada. Na pesquisa, verificou-se que em torno de $80 \%$ das ações propostas são julgadas procedentes no mérito. De acordo com a pesquisa, os juízes defendem, preponderantemente, a inaplicabilidade do princípio da reserva do possível e a observância aos princípios da universalidade de acesso à saúde, de maneira que não se "percebem controvérsias de entendimento, porquanto predominantemente decidem em unanimidade, o que tem possibilitado a construção de uma jurisprudência sólida e perene no assunto" ${ }^{12}$.

A discussão sobre o acesso às ações e serviços de saúde pela via judicial no Brasil ganhou importância teórica e prática, ao suscitar crescentes debates entre

\footnotetext{
9SOARES, J. C. R. D. S; DEPRÁ, A. S. Ligações Perigosas: indústria farmacêutica, associações de pacientes e as batalhas judiciais por acesso a medicamentos. Physis: Revista de Saúde Coletiva, Rio de Janeiro, v. 22, p. 312, 2012. Disponível em: <www.scielo.br/scielo.php?script=sci_arttext\&pid=S0103-73312012000100017>. http://dx.doi.org/10.1590/S0103-73312012000100017.

${ }^{10}$ BRASIL. Conselho Nacional de Secretários da Saúde. Direito à saúde: coleção para entender a gestão do SUS, cit., p. 62.

${ }^{11}$ FLEURY, Sonia; FARIA, Mariana. A Judicialização como ameaça e salvaguarda do SUS. In: SANTOS, Lenir; TERRAZAS, Fernanda (Org.). Judicialização da saúde no Brasil.Campinas: Saberes Ed., 2014. p. 109.

${ }^{12}$ Relatório de pesquisa "A saúde pública jurisdicionalizada no Estado do Pará", realizada no âmbito do Programa de Bolsas de Iniciação Científica e Tecnológica (PIBICT), do Centro Universitário do Pará (CESUPA), pela pesquisadora Juliana Melo Corrêa Albuquerque de Oliveira, sob a orientação de Loiane da Ponte Souza Prado Verbicaro, no período de fevereiro a dezembro de 2013. OLIVEIRA, Juliana Melo Corrêa Albuquerque; VERBICARO, Loiane Prado. A saúde pública jurisdicionalizada no Estado do Pará: Centro Universitário do Estado do Pará, Belém, 2013.
} 
acadêmicos, operadores do direito, gestores públicos, profissionais de saúde e sociedade civil, trazendo para o centro da discussão a atuação do Poder Judiciário em relação à garantia do direito à saúde ${ }^{13}$.

Nessa direção, o presente trabalho abordará a saúde como um direito social judicializado, bem como apresentará a Ação Civil Pública n. 0021681-17.2011.8.14.0301, que trata do acesso ao hormônio do crescimento no âmbito do Estado do Pará. Fará também considerações sobre questões técnicas e éticas acerca do uso do hormônio do crescimento e das vias de acesso a esse medicamento pelo Sistema Único de Saúde. E, por fim, buscará demonstrar a necessidade da aplicação de parâmetros técnicos na análise de ações judiciais cujo objeto pretendido seja o fornecimento de medicamentos, à luz de um caso concreto.

\section{Saúde como um direito social judicializado}

C. Neal Tate e Torbjörn Vallinder definiram a judicialização da política como o fenômeno de transferência de decisão da legislatura, do gabinete ou da administração pública às cortes judiciais ("from without"), bem como a propagação dos métodos judiciais de decisão para fora das cortes de Direito propriamente ditas ("from within") ${ }^{14}$.

Os autores, ao investigarem o expansionismo judicial na arena política e social, analisaram os fatores que impulsionaram o crescimento da dimensão política dos juízes. Segundo eles, a expansão do Poder Judiciário nas democracias contemporâneas, resultado do desenvolvimento histórico das instituições democráticas, está associada ao fim do comunismo no Leste Europeu e à difusão do funcionamento institucional do sistema jurídico norte-americano de revisão judicial (judicial review).

Dessa forma, o modelo de revisão judicial contemplado nos Estados Unidos tornou-se o paradigma de controle judicial a ser seguido por outros países, especialmente pelas novas democracias. Segundo os autores, na Europa os direitos humanos tiveram, também, um papel fundamental, por terem disseminado a judicialização nos mais diversos países da região - sendo a difusão do poder judicial entendida como um avanço na ideia de limites jurídicos impostos pelo Estado à sociedade, inclusive ao próprio Estado $^{15}$.

\footnotetext{
${ }^{13}$ BLIACHERIENE, Ana Carla; RUBIN, Thiago; SANTOS, José Sebastião dos. op. cit., p. 352.

${ }^{14}$ TATE, Neal; VALLINDER, T. The global expansion of judicial power. New York: New York University Press, 1995. p. 27-36.

${ }^{15}$ Para Antoine Garapon, por trás do fenômeno da judicialização da política existe uma ampliação da aplicabilidade do direito sem precedentes na história do mundo ocidental. Os fatores que mais influenciaram esse processo foram: o fim da Guerra Fria e do socialismo real; a internacionalização do direito como ordenador do poder supranacional; e a crise de legitimidade representativa. GARAPON, Antoine. 0 juiz e a democracia: o guardião das promessas. Rio de Janeiro: Renavan, 2001. p. 23-53.
} 
Neal Tate, ao analisar esse fenômeno, estabeleceu as condições necessárias ou facilitadoras do surgimento do processo de judicialização da política. São elas:

(a) A institucionalização de uma ordem democrática.

(b) A separação dos poderes do Estado e a independência do Judiciário.

(c) A universalização do acesso ao sistema de justiça.

(d) A existência de uma Constituição (política de afirmação de direitos) que explicite direitos e valores, os quais possam ser invocados em defesa dos indivíduos e grupos que se sintam lesados pela vontade da maioria.

(e) O uso dos tribunais por grupos minoritários de interesse para a realização de seus direitos.

(f) O uso dos tribunais pela oposição para frear e controlar as deliberações majoritárias da arena política.

(g) A ineficácia das instâncias majoritárias de formação da vontade política. Tal ineficácia tem-se materializado na ausência e/ou insuficiência das políticas públicas acertadas na arena política e na debilidade dos partidos políticos em governar com a maioria do Parlamento, gerando, com isso, uma espécie de crise de governabilidade, paralisia no processo decisório e o consequente esvaziamento das funções do Congresso, o que culmina, quase sempre, em demandas ao Poder Judiciário.

(h) Instituições majoritárias que, em alguns casos, deleguem ao Poder Judiciário o custo político de uma decisão polêmica. Trata-se de um ato de renúncia à prerrogativa de decidir a fim de evitar o enfrentamento direto com questões fortemente controvertidas em termos morais e de grande magnitude e impacto à sociedade.

Seguindo essa tendência, no Brasil, assim como nas principais democracias ocidentais, esse fenômeno foi gradativamente se consolidando após a CF/88. $\mathrm{O}$ direito à saúde e seus princípios correlatos apresentam uma evidente textura aberta e isso, ao mesmo tempo em que exige uma normatividade ulterior em razão da abrangência semântica das normas, enseja uma crescente proposição de demandas aos tribunais na garantia do direito à saúde ${ }^{16}$.

A CF/88, ao tornar a saúde um direito universal, trouxe avanços e, paralelamente, novos desafios para sua implementação e efetivação. As disposições constitucionais sobre uma política integrada de saúde, somadas aos dispositivos infraconstitucionais que buscaram regulamentar essa política, ao menos em tese, estabeleceram um panorama legislativo capaz de efetivar esse direito. No plano prático, entretanto, restou escassamente constatada a realização do direito à saúde.

\footnotetext{
${ }^{16}$ VERBICARO, Loiane Prado. Um estudo sobre as condições facilitadoras da judicialização da política no Brasil. Revista Direito GV, v. 4, n. 8, jul./dez. 2008.
} 
Embora o SUS represente uma importante política pública que visa ao acesso universal e igualitário e à atenção integral, o sistema não conseguiu evoluir na medida das necessidades da população de um país continental como o Brasil.

Mesmo após duas décadas da promulgação da $\mathrm{CF} / 88$ que garantiu a universalização dos direitos sociais, o orçamento da Seguridade Social que a consagraria nunca se materializou, frustrando parte da dimensão universalizante do projeto da Seguridade Social brasileira ${ }^{17}$.

Tais limites encontrados pelo SUS evidenciam a seguinte contradição: a própria "Constituição Cidadã", assim declarada no ato de sua proclamação, tem como finalidade garantir direitos coletivos na área da saúde que, na prática, não são assegurados plenamente. A partir dessa contradição, diversos grupos da sociedade têm buscado a materialização desses direitos, articulando novas estratégias de luta no campo do direito.

Nesse contexto, salienta-se uma tendência crescente no âmbito da doutrina e da jurisprudência brasileira no sentido da afirmação da exigibilidade judicial de posições subjetivas, ligadas ao chamado mínimo existencial - que, de acordo com a compreensão prevalente, vai além da mera sobrevivência física para albergar a garantia de condições materiais mínimas para uma vida saudável ${ }^{18}$.

Diante de um contexto de recursos escassos, aumento da expectativa de vida e multiplicação de doenças, o poder público apresenta dificuldade de transpor o direito à saúde para a prática - ou seja, cumpri-lo efetivamente -, o que estimula o manejo de ações judiciais a fim de compelir o Estado a fornecer os bens e serviços relacionados à saúde.

No entanto, esse cenário de transferência de demandas ao Judiciário gera a necessidade de se refletir acerca de algumas consequências inevitáveis desse fenômeno.

Para Sarmento e Telles,

a problemática subjacente ao direito à saúde envolve sobretudo questões de justiça distributiva, de natureza multilateral, visto que, diante da escassez, garantir prestações a alguns significa retirar recursos do bolo que serve aos demais. Boas decisões nesta área pressupõem, portanto, a capacidade de formar uma adequada visão de conjunto, o que é muito difícil de alcançar no âmbito de um processo judicial ${ }^{19}$.

\footnotetext{
${ }^{17}$ MACHADO, Felipe Rangel de Souza; DAIN, Sulamis. Direito e saúde: contribuições para o estudo da judicialização. In: ASENSI, Felipe Dutra; PINHEIRO, Roseni (Orgs.). Direito sanitário. Rio de Janeiro: Elsevier, 2012. p. 464.

${ }^{18}$ FIGUEIREDO Mariana Filchtiner; SARLET, Ingo Wolfgang. Notas sobre o direito fundamental à proteção e promoção da saúde na ordem jurídico-constitucional brasileira. In: ASENSI, Felipe Dutra; PINHEIRO, Roseni (Orgs.). Direito sanitário. Rio de Janeiro: Elsevier, 2012. p. 36.

${ }^{19}$ SARMENTO, Daniel; TELLES, Cristina. Judicialização da saúde e responsabilidade federativa: solidariedade ou subsidiariedade? In: ASENSI, Felipe Dutra; PINHEIRO, Roseni (Orgs.). Direito Sanitário. Rio de Janeiro: Elsevier, 2012. p.125.
} 
Não há como, pura e simplesmente, negligenciar o problema da limitação dos recursos públicos (e privados) para assegurar o direito fundamental à saúde, o que envolve a questão da chamada "reserva do possível" e o debate em torno das decisões acerca da alocação de recursos públicos. O argumento da reserva do possível se desdobra em pelo menos dois aspectos: um primeiro de contornos eminentemente fáticos, e outro, de cunho prevalentemente jurídico. $\mathrm{O}$ aspecto fático apresenta caráter econômico e se reporta à limitação dos recursos disponíveis, refletindo a indagação sobre a existência, a disponibilização e a alocação dos recursos públicos ${ }^{20}$.

Obviamente a questão do orçamento deve ser revista, até porque é visível aos olhos da sociedade a falta de recursos para esse setor. E, mesmo que os recursos fossem suficientes para arcar com os principais serviços de saúde para toda a população, repetidas demandas para aquisição de determinados bens ou serviços bastariam para desestabilizar financeiramente a gestão de muitos sistemas de saúde ${ }^{21}$.

$\mathrm{O}$ atual quadro das demandas judiciais em saúde expõe situações extremas e opiniões diversas. Cada ator envolvido nessas demandas tem uma interpretação sobre esse fenômeno. Podem-se destacar ao menos quatro fatores fundamentais na geração das demandas judiciais em saúde: (a) insuficiência do sistema (caso em que o serviço de saúde não fornece os medicamentos que constam nas listas oficiais do SUS); (b) vazios assistenciais (na hipótese de doença que não tem protocolo clínico elaborado pelo SUS); (c) conflito entre evidência científica e opinião médica (quando há prescrição de medicamento fora da bula ou discordante dos protocolos do SUS); e (d) mercantilização da saúde (na hipótese de indução de incorporação tecnológica e de medicamentos estimulados por grupos empresariais e laboratórios) ${ }^{22}$.

Nesse sentido, o Judiciário tem sido cada vez mais chamado a resolver inúmeros conflitos concretos sobre o direito à saúde e, uma vez que lhe é vedado deixar de decidir, em razão do non liquet, alargou suas hipóteses de intervenção direta e de controle, inclusive sobre as políticas públicas. É possível até mesmo se referir, em hipóteses mais extremas, a uma hipertrofia jurisdicional dessa seara - o que hoje vem sendo substituído pela busca de critérios práticos e objetivos para a aferição das pretensões formuladas, a partir de um diálogo interdisciplinar (mediante, por exemplo, a consideração dos princípios da Bioética, da utilização da "medicina de evidências" e de critérios para o uso racional de medicamentos) e interinstitucional, dos quais são exemplos os projetos pioneiros de criação de mecanismos de conciliação pré-judicial nesse campo ${ }^{23}$.

O Supremo Tribunal Federal (STF), provocado a se manifestar sobre políticas de ação afirmativa, entre elas a judicialização da saúde, adotou audiências públicas como estratégia para obter subsídios para suas decisões.

\footnotetext{
${ }^{20}$ FIGUEIREDO Mariana Filchtiner; SARLET, Ingo Wolfgang. op. cit., p. 59.

${ }^{21}$ MACHADO, Felipe Rangel de Souza; DAIN, Sulamis. op. cit., p. 470.

${ }^{22}$ Id. Ibid. 478.

${ }^{23}$ FIGUEIREDO Mariana Filchtiner; SARLET, Ingo Wolfgang. op. cit., p. 57.
} 
A Audiência Pública n. 04 foi realizada de abril a maio de 2009 (Audiência Pública n. 04/2009) e, no Despacho de Convocação de Audiência Pública ${ }^{24}$, o presidente do STF na época, Gilmar Mendes, justificou a convocação considerando os diversos pedidos de suspensão de segurança, suspensão de liminar e suspensão de tutela antecipada em trâmite, os quais objetivam suspender medidas cautelares que determinam o fornecimento das mais variadas prestações de saúde pelo SUS (fornecimento de medicamentos, suplementos alimentares, órteses e próteses; criação de vagas de UTI; contratação de servidores de saúde; realização de cirurgias; custeio de tratamentos fora do domicílio e de tratamentos no exterior; entre outros); que tais decisões suscitavam inúmeras alegações de lesão à ordem, à segurança, à economia e à saúde pública; a repercussão geral e o interesse público relevante das questões suscitadas.

A partir dos resultados da Audiência Pública n. 4/2009, o Conselho Nacional de Justiça (CNJ) constituiu um grupo de trabalho para estudo e proposta de medidas concretas e normativas para as demandas judiciais envolvendo a assistência à saúde. Os trabalhos do grupo culminaram na aprovação pelo Plenário do CNJ da Recomendação n. $31 / 2010^{25}$, que traça diretrizes para os magistrados quanto às demandas judiciais que envolvem a assistência à saúde e recomenda aos tribunais a adoção de medidas visando a melhor subsidiar os magistrados e demais operadores do direito para assegurar a maior eficiência na solução das demandas judiciais envolvendo a assistência à saúde ${ }^{26}$.

A busca pelo melhor entendimento das especificidades do subsistema sanitário também pode ser observada na Resolução n. 107/201027 do CNJ, que institui o Fórum Nacional do Judiciário para monitoramento e resolução das demandas de assistência à saúde, e na Recomendação n. 43/2013 ${ }^{28}$ do CNJ, que estabelece aos tribunais de justiça e aos tribunais regionais federais que promovam a especialização de Varas para processar e julgar ações que tenham por objeto o direito à saúde pública e para priorizar o julgamento dos processos relativos à saúde suplementar.

\footnotetext{
${ }^{24}$ BRASIL. SUPREMO TRIBUNAL FEDERAL. Despacho Convocatório - STF. Disponível em: <http://www.stf.jus. br/arquivo/cms/processoAudienciaPublicaSaude/anexo/Despacho_Convocatorio.pdf>.

${ }^{25}$ CONSELHO NACIONAL DE JUSTIÇA. Recomendação n. 31, de 30 de março de 2010. Recomenda aos Tribunais a adoção de medidas visando a melhor subsidiar os magistrados e demais operadores do direito, para assegurar maior eficiência na solução das demandas judiciais envolvendo a assistência à saúde. Disponivel em: <http://www.cnj.jus.br/atos-normativos?documento=877>. Acesso em: 31 jan. 2017.

${ }^{26}$ TERRAZAZ, Fernanda. Novos elementos no cenário da judicialização da saúde: análise das decisões dos tribunais superiores. In: SANTOS, Lenir; TERRAZAS, Fernanda (Org.). Judicialização da saúde no Brasil. Campinas: Saberes Ed., 2014. p. 333

${ }^{27}$ CONSELHO NACIONAL DE JUSTIÇA. Recomendação n. 107, de 6 de abril de 2010. Institui o Fórum Nacional do Judiciário para monitoramento e resolução das demandas de assistência à saúde. Disponível em: <http://www.cnj.jus.br/atos-normativos?documento=173>. Acesso em: 31 jan. 2017.

${ }^{28}$ CONSELHO NACIONAL DE JUSTIÇA. Recomendação n. 43, de 20 de agosto de 2013. Recomenda aos Tribunais de Justiça e aos Tribunais Regionais Federais que promovam a especialização de Varas para processar e julgar ações que tenham por objeto o direito à saúde pública e para priorizar o julgamento dos processos relativos à saúde suplementar. Disponível em: <http://www.cnj.jus.br/atosnormativos?documento=1823>. Acesso em: 31 jan. 2017.
} 


\section{A Judicialização do acesso ao hormônio do crescimento no Estado do Pará: o caso concreto}

O Ministério Público do Estado do Pará (MPE) ajuizou a Ação Civil Pública (ACP) 0021681-17.2011.814.0301 ${ }^{29}$ com pedido liminar em face do Estado do Pará/Secretaria Executiva de Saúde Pública (SESPA), visando a compelir o Estado a fornecer o medicamento Hormotrop ${ }^{\circledR}$ - Somatropina 12 UI (Unidade Internacional) para todas as crianças e adolescentes que estejam com deficiência na produção de hormônio do crescimento, sem interrupção.

A ação foi originada no pedido da mãe de um menor impúbere, sob a alegação de que o filho era usuário do SUS e realizava tratamento para deficiência do hormônio do crescimento com o medicamento Somatropina 12 UI de nome comercial Hormotrop ${ }^{\circledR}$ fornecido pela SESPA, mas que o órgão não estava fornecendo o medicamento e, portanto, o filho não estava tendo acesso ao tratamento a que tinha direito.

O MPE, na qualidade de substituto processual e aduzindo que a falta do medicamento colocaria em risco a vida e a saúde de crianças e adolescentes, bem como direitos indisponíveis e imprescritíveis afetos à personalidade, ajuizou a referida ACP pedindo a concessão de medida liminar para que o Estado regularizasse o fornecimento imediato do medicamento.

O pedido liminar foi deferido em 29 de setembro de 2011 e, na decisão prolatada, determinou-se que

O Estado do Pará promova imediatamente o fornecimento do medicamento Hormotrop ${ }^{\circledR}$ - Somatropina 12 UI para todas as crianças e adolescentes que estejam com deficiência na produção de hormônio de crescimento, sem interrupção, pois o remédio é de uso diário, a fim de que sejam evitados danos posteriores, sob pena de multa diária de $\mathrm{R} \$ 2.000,00$ (dois mil reais) ${ }^{30}$.

Essa decisão foi objeto de recurso, havendo a interposição do agravo de instrumento com pedido de efeito suspensivo, sob as alegações de que (a) não cabe ao Judiciário brasileiro intervir em políticas públicas, pois existem limites orçamentários; (b) devem ser respeitados os princípios da reserva do possível e da universalidade de acesso; (c) houve invasão do juízo de conveniência e oportunidade da Administração; e (d) a interrupção do fornecimento se deu por motivo alheio a sua vontade, qual seja, a falta de matéria-prima para a fabricação do medicamento pelo laboratório.

\footnotetext{
${ }^{29}$ ANDAMENTO do Processo n. 00216811720118140301 - 03/09/2015 do TJPA. Diário de Justiça do Estado do Pará, 14/04/2012. JusBrasil. Andamento do Processo n. 00216811720118140301 - 03/09/2015 do TJPA. Disponível em: <http://www.jusbrasil.com.br/diarios/documentos/227375172/andamento-doprocesso-n 00216811720118140301-03-09-2015-do-tjpa>. Acesso em: 31 jan. 2017.

${ }^{30}$ DIÁRIO de Justiça do Estado do Pará, 14/04/2012. JusBrasil. Disponível em: <http://www.jusbrasil.com. br/diarios/36035869/djpa-12-04-2012-pg-67>.
} 
Em 30 de março de 2012, a decisão que concedeu a tutela antecipatória foi mantida, tendo em vista que a ausência do medicamento poderia gerar o agravamento da saúde e o mau desenvolvimento de crianças e adolescentes que deles necessitam e, em decisão monocrática, o agravo de instrumento foi convertido em agravo retido, por ausência de motivos a justificar lesão grave e de difícil reparação aduzidas pelo agravante.

A sentença que decidiu o caso, publicada em $1^{\circ}$ de dezembro de 2014, ratificou a liminar concedida anteriormente. $O$ pedido formulado na inicial foi julgado procedente e ficou determinando que o Estado do Pará e a SESPA procedessem a imediata disponibilização do medicamento Hormotrop ${ }^{\circledR}$ - Somatropina 12 UI para todas as crianças e adolescentes que estivessem com deficiência na produção de hormônio do crescimento.

Para melhor compreensão do tema, serão abordados conceitos relacionados ao medicamento objeto da presente ação e breves aspectos éticos e psicológicos relacionados à questão da baixa estatura.

\section{O hormônio do crescimento e os aspectos éticos e psicossociais relacionados à baixa estatura}

O hormônio do crescimento $(\mathrm{GH})$, também denominado somatropina, é uma proteína sintetizada e excretada por células especiais da adenohipófise e age no organismo como um todo, promovendo não só o crescimento longitudinal, mas o das células em geral. É responsável por grande parte do anabolismo do corpo - crescimento de ossos e tecidos -, além de participar da regulação do metabolismo de proteínas lipídios e carboidratos ${ }^{31}$.

Os distúrbios que refletem as ações do hormônio do crescimento são mais evidentes em crianças. Deficiências graves na infância levam ao nanismo, o qual pode resultar de um problema na síntese do hormônio do crescimento ou em receptores de GH defeituosos. No extremo oposto, sua hipersecreção em crianças leva ao gigantismo ${ }^{32}$.

A deficiência de $\mathrm{GH}$ em crianças é caracterizada por baixa estatura (BE); e, em adultos, por aumento da gordura intra-abdominal, redução da massa corporal magra, hipoglicemia, diminuição do vigor e isolamento social. Adultos com secreção excessiva do hormônio do crescimento desenvolvem uma condição conhecida como acromegalia, caracterizada pelo alongamento da mandíbula e pelo crescimento das mãos e pés, além de traços faciais tornarem-se grosseiros ${ }^{33}$.

\footnotetext{
${ }^{31}$ MATFIN, Glenn; PORTH, Carol Mattson. Fisiopatologia. Tradução de: Pathophysiology: concepts of altered health states. $8^{\text {th }}$ ed. Rio de Janeiro: Guanabara Koogan, 2010. p. 1046.

${ }^{32}$ SILVERTHORN, Dee Unglaub. Fisiologia humana: uma abordagem integrada. 5. ed. Porto Alegre: Artmed, 2010. p. 770.

${ }^{33}$ CENTRO COLABORADOR DO SUS: AVALIAÇÃO DE TECNOLOGIAS E EXCELÊNCIA EM SAÚDE (CATES). Universidade Federal de Minas Gerais. Avaliação comparativa das apresentações de Somatropina disponibilizadas pelo SUS e demais comercializadas. Belo Horizonte, 2015. 57 p. Disponível em: <http://www.ccates.org.br/content/_ pdf/PUB_1426103238.pdf>. Acesso em: 25 mar. 2016.
} 
O tratamento da BE com GH tem sido utilizado há várias décadas - inicialmente em pacientes com deficiência de GH e, logo a seguir, com doenças genéticas, como a síndrome de Turner, e crônicas, como a insuficiência renal. Um número significante de pacientes tratados com GH corresponde a crianças e adolescentes com baixa estatura idiopática (BEI). Longui, em estudo sobre o uso de GH em pacientes com BEI, descreve três subclasses de diagnósticos: a baixa estatura familiar, o retardo constitucional do crescimento e da puberdade e a baixa estatura idiopática propriamente dita. Quanto à baixa estatura idiopática propriamente dita, afirma que "a investigação etiológica não permite identificar a causa da perda estatural e o quadro permanece verdadeiramente idiopático ao longo do seguimento clínico" ${ }^{34}$.

Consta na literatura o uso de GH para o tratamento da Baixa Estatura (BE) na Síndrome de Prader-Willi, em crianças nascidas com baixo peso (PIG), na Síndrome de Noonan e em casos de Síndrome da Imunodeficiência Adquirida.

Atualmente a somatropina é produzida por diferentes indústrias farmacêuticas e com diferentes nomes comerciais, a saber: Biomatrop ${ }^{\circledR}$, Eutropin $^{\circledR}$, Genotropin $^{\circledR}$,

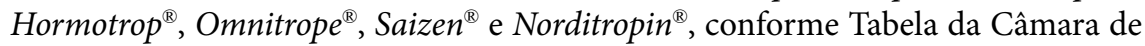
Regulação de Medicamentos da Agência Nacional de Vigilância Sanitária (Anvisa) ${ }^{35}$.

A estatura é uma variável antropométrica frequentemente utilizada para demonstrar o histórico de nutrição da pessoa, ao indicar os efeitos de fatores econômicos e sociais da população. No Brasil, o IBGE desenvolve em parceria com o Ministério da Saúde a Pesquisa de Orçamento Familiar (POF), que fornece informações sobre o estado nutricional da população residente no país e apresenta estatísticas a partir da coleta de dados (entre eles, a medida de peso e altura de crianças, adolescentes e adultos). Os dados são contrastados com os padrões estabelecidos pela $\mathrm{OMS}^{36}$ com o objetivo de diagnosticar problemas no padrão de crescimento de crianças e adolescentes, por exemplo. A mais recente POF, realizada no período de 2008 a 2009, revela que a altura mediana de crianças e adolescentes brasileiros evoluiu e segue na direção do padrão internacional estabelecido pela $\mathrm{OMS}^{37}$.

\footnotetext{
${ }^{34}$ LONGUI, Carlos Alberto. Uso de GH em Pacientes com Baixa Estatura Idiopática. Arq. Bras. Endocrinol Metab, São Paulo, v. 5, n. 52, p.750, dez. 2008.

${ }^{35}$ AGÊNCIA NACIONAL DE VIGILÂNCIA SANITÁRIA. Câmara de Regulação - CMED Secretaria Executiva. Disponível em: <http://portal.anvisa.gov.br/documents/374947/2829072/LISTA_CONFORMIDADE_GOV_2016-05-23.pdf/ c9eefbc3-28b1-485d-95bd-66fb6b65c21e>. Acesso em: 31 jan. 2017.

${ }^{36}$ As curvas da OMS adaptam-se bem ao padrão de crescimento das crianças e adolescentes e aos pontos de corte de sobrepeso e obesidade recomendados para os adultos. Dessa forma, a referência da OMS preenche a lacuna antes existente nas curvas de crescimento e correspondem à referência adequada para a avaliação nutricional das crianças e adolescentes do nascimento aos 19 anos, razão esta que fez este Ministério adotar essa referência para o Brasil. MINISTÉRIO DA SAÚDE. Curvas de Crescimento da Organização Mundial da Saúde - OMS. Disponível em: <http://dab.saude.gov.br/portaldab/ape_ vigilancia_alimentar.php?conteudo=curvas_de_crescimento>. Acesso em: 31 jan. 2017.

${ }^{37}$ INSTITUTO BRASILEIRO DE GEOGRAFIA E ESTATÍSTICA. Antropometria e estado nutricional de crianças, adolescentes e adultos no Brasil: POF 2008-2009. Brasil, 2010. 42 p. Disponível em: <http://www.ibge. gov.br/home/estatistica/populacao/condicaodevida/pof/2008_2009_encaa/pof_20082009_encaa. pdf>. Acesso em: 14 mar. 2015. Acesso em: 31 jan. 2017.
} 
Sholl-Franco et al. descrevem que a altura não é somente consequência das condições sociais, mas também causa de posicionamento ou inserção de indivíduos ${ }^{38}$. Acrescentam que, em nossa cultura, a estatura é relacionada à boa nutrição e ao bem-estar, e também a status social, uma vez que desde os tempos mais remotos a altura tem sido relacionada a poder. Para os autores, nem sempre a terapia com o GH é realizada em pessoas que realmente possuem algum tipo de deficiência de produção, e o principal motivo dos pais para expor o filho a esse tratamento seria, portanto, a pretensão de que este possa crescer mais e, assim, alcançar um padrão de altura mais desejável ${ }^{39}$.

\section{Portas de acesso ao hormônio do crescimento no SUS}

A Lei n. 8.080/1990 ${ }^{40}$, prevê a assistência farmacêutica no campo de atuação do SUS e o Decreto n. 7.508/2011 ${ }^{41}$, que regulamenta a referida lei, estabelece a Relação Nacional de Medicamentos Essenciais (Rename) como o padrão de medicamentos indicados para o atendimento de doenças ou de agravos no âmbito o SUS, tendo seu elenco definido na Portaria MS/GM n. 1/2015 $5^{42}$

A Portaria MS/GM n. 204/2007³, que regulamenta a transferência de recursos que viabilizam a execução das ações e serviços de saúde no âmbito do SUS, enquadra a assistência farmacêutica como bloco específico de financiamento constituído pelos Componentes Básico da Assistência Farmacêutica (CBAF), o Componente Estratégico da Assistência Farmacêutica e o Componente Especializado da Assistência Farmacêutica (CEAF).

O hormônio do crescimento está incluído na lista de medicamentos padronizados no CEAF, que é definido no artigo $2^{\circ}$ da Portaria GM/MS n. 1554/2013 ${ }^{44}$, como uma estratégia de acesso a medicamentos no âmbito do SUS e caracterizado pela busca da garantia da integralidade do tratamento medicamentoso, em nível

${ }^{38}$ SHOLL-FRANCO, Alfred et al. A influência da baixa estatura sobre as representações psicossociais e a utilização do hormônio do crescimento. Ciências e Cognição, v. 2, 2004, p. 55, 2004. Disponível em: <http://cienciasecognição.org/revista/index.php/cec/aticle/view/30/23>. Acesso em: 10 abr. 2015.

${ }^{39}$ Id. Ibid., p. 51.

${ }^{40}$ BRASIL. Lei n. 8.080, de 19 de setembro de 1990, cit.

${ }^{41}$ BRASIL. Decreto n. 7.508, de 28 de junho de 2011. Regulamenta a Lei 8080 de 19 de setembro de 1990, para dispor sobre a organização do SUS, o planejamento da saúde, a assistência à saúde e a articulação interfederativa e dá outras providências. Disponível em: < http://www.planalto.gov.br/ccivil_03/_ato20112014/2011/decreto/D7508.htm>. Acesso em: 31 jan. 2017.

${ }^{42}$ MINISTÉRIO DA SAÚDE. Gabinete do Ministro. Portaria n. 01, 01 de janeiro de 2015. Estabelece a Relação Nacional de Medicamentos - RENAME 2014 no âmbito do SUS por meio da atualização do elenco de medicamentos e insumos da RENAME 2012. Disponível em: <http://bvsms.saude.gov.br/bvs/saudelegis/ gm/2015/prt0001_02_01_2015.html>. Acesso em: 31 jan. 2017.

${ }^{43}$ MINISTÉRIO DA SAÚDE. Gabinete do Ministro. Portaria n. 204, de 29 de janeiro de 2007. Regulamenta o financiamento e a transferência de recursos federais para as ações e os serviços de saúde, na forma de bloco de financiamento, com o respectivo monitoramento e controle. Disponível em: <http://bvsms.saude. gov.br/bvs/saudelegis/gm/2007/prt0204_29_01_2007_comp.html>. Acesso em: 31 jan. 2017.

${ }^{44}$ MINISTÉRIO DA SAÚDE. Gabinete do Ministro. Portaria n. 1554, de 30 de julho de 2013. Dispõe sobra as regras de financiamento e execução do Componente Especializado da Assistência Farmacêutica no âmbito do SUS. Disponível em: <http://portalarquivos.saude.gov.br/images/pdf/2014/abril/02/pt-gm-ms-15542013-alterada-1996-2013.pdf>. Acesso em: 31 jan. 2017. 
ambulatorial, cujas linhas de cuidado estão definidas em protocolos clínicos e diretrizes terapêuticas (PCDT) publicados pelo Ministério da Saúde.

Os protocolos clínicos têm o objetivo de esclarecer os critérios de diagnósticos da cada doença, os critérios de inclusão e exclusão de pacientes, o tratamento e as doses corretas dos medicamentos indicados, bem como os mecanismos de controle, acompanhamento e avaliação.

A incorporação, exclusão, ampliação ou redução de cobertura de medicamentos no âmbito do CEAF ocorre mediante decisão do Ministério da Saúde, assessorado pela Comissão Nacional de Incorporação de Tecnologias do SUS (Conitec) e conforme a previsão legal da Lei n. 12.401/2011 ${ }^{45}$.

Atualmente, o hormônio do crescimento é fornecido pelo SUS para o tratamento da deficiência do hormônio do crescimento (hipopituitarismo) - identificada no Código Internacional de Doenças pelo CID-10 E23 e com PCDT estabelecido na Portaria SAS/ MS n. 110/2010 46 - e da Síndrome de Turner - nos CID’s-10 Q96.0, Q96.1, Q96.2, Q96.3, Q96.4 e Q96.8, com PCDT estabelecido na Portaria SAS/MS n. 223/20107.

O fármaco definido para o tratamento das referidas patologias é a somatropina, disponibilizada em duas apresentações: frasco-ampola de 4 UI e frasco-ampola de 12 UI. A solicitação do tratamento ocorrerá somente em estabelecimentos de saúde vinculados às unidades públicas designadas pelos gestores estaduais de saúde, conforme prevê o artigo $24^{\circ}$ da Portaria GM/MS n. 1554/2013 ${ }^{48}$. Seu fornecimento depende do pedido específico de cada paciente, que será submetido a análise individualizada. O procedimento de execução do CEAF definido na Portaria GM/MS n. $1554 / 2013^{49}$, prevê o cumprimento das etapas de solicitação, avaliação e emissão da Autorização de Procedimento de Alto Custo (APAC) para, então, haver a dispensação, quando o paciente receberá o medicamento assim como as orientações de como administrar e armazenar adequadamente o mesmo.

Quanto ao financiamento, os medicamentos que compõem o CEAF são definidos de acordo com critérios, quais sejam: a complexidade do tratamento da doença, a garantia da integralidade do tratamento da doença e a manutenção do equilíbrio financeiro entre as esferas de gestão do SUS.

\footnotetext{
${ }^{45}$ BRASIL. Lei n. 12.401, de 28 de abril de 2011. Altera a Lei no 8080 de 19 de setembro de 1990, para dispor sobre a assistência terapêutica e a incorporação de tecnologia em saúde no âmbito do SUS. Disponível em: < http://www.planalto.gov.br/CCIVIL_03/_Ato2011-2014/2011/Lei/L12401.htm>. Acesso em: 31 jan. 2017.

${ }^{46}$ MINISTÉRIO DA SAÚDE. Secretaria de Atenção à Saúde. Portaria n. 110, de 10 de março de 2010. Disponivel em: <http://bvsms.saude.gov.br/bvs/saudelegis/sas/2010/prt0110_10_03_2010_rep.html>. Acesso em: 31 jan. 2017.

${ }^{47}$ MINISTÉRIO DA SAÚDE. Secretaria de Atenção à Saúde. Portaria n. 223, de 10 de maio de 2010. Disponível em: <http://bvsms.saude.gov.br/bvs/saudelegis/sas/2010/prt0110_10_03_2010_rep.html>. Acesso em: 31 jan. 2017.

${ }^{48}$ MINISTÉRIO DA SAÚDE. Gabinete do Ministro. Portaria n. 1554, de 30 de julho de 2013, cit.

${ }^{49}$ Id. Ibid.
} 
O artigo $3^{\circ}$ da Portaria GM/MS n. $1554 / 2013^{50}$, divide os medicamentos em três grupos:

(a) Grupo 1: Estão incluídos os medicamentos sob responsabilidade de financiamento pelo Ministério da Saúde, sendo dividido em:

(i) Grupo 1A: medicamentos com aquisição centralizada pelo Ministério da Saúde e fornecidos às secretarias de saúde dos estados e Distrito Federal, sendo delas a responsabilidade pela programação, armazenamento, distribuição e dispensação para tratamento das doenças contempladas no âmbito do componente Especializado da Assistência Farmacêutica.

(ii) Grupo 1B: medicamentos cofinanciados pelo Ministério da Saúde mediante transferência de recursos financeiros às secretarias de saúde dos estados e Distrito Federal para aquisição, programação, armazenamento, distribuição e dispensação para tratamento das doenças contempladas no âmbito do Componente Especializado da Assistência Farmacêutica.

(b) Grupo 2: medicamentos sob a responsabilidade das secretarias de saúde dos estados e do Distrito Federal para financiamento, aquisição, programação, armazenamento, distribuição e dispensação para tratamento das doenças contempladas no âmbito do Componente Especializado da Assistência Farmacêutica.

(c) Grupo 3: medicamentos sob a responsabilidade das secretarias de saúde dos estados e do Distrito Federal e dos municípios para aquisição, programação, armazenamento, distribuição e dispensação e que está estabelecida em ato normativo específico que regulamenta o Componente Básico da Assistência Farmacêutica.

A Portaria GM/MS n. 1554/2013 ${ }^{51}$, prevê o financiamento da somatropina no grupo $1 \mathrm{~B}$ - dos medicamentos cofinanciados pelo Ministério da Saúde mediante transferência de recursos financeiros às secretarias de saúde dos estados e Distrito Federal para aquisição, programação, armazenamento, distribuição e dispensação para tratamento das doenças contempladas no âmbito do Componente Especializado da Assistência Farmacêutica.

O Ministério da Saúde define competências e organiza o sistema de acordo com critérios e responsabilidades de financiamento, execução e dispensação, para facilitar o acesso e viabilizar a política pública, de acordo com as disponibilidades orçamentárias e financeiras de cada ente e a proximidade com o paciente ${ }^{52}$.

\footnotetext{
${ }^{50}$ MINISTÉRIO DA SAÚDE. Gabinete do Ministro. Portaria n. 1554, de 30 de julho de 2013, cit.

${ }^{51}$ Id. Ibid.

${ }^{52}$ FREITAS, Cristina Leitão Teixeira. Judicialização da saúde, solidariedade e ressarcimento: destaques da posição dos Estados frente a polarização de entendimentos. In: SANTOS, Lenir; TERRAZAS, Fernanda (Org.). Judicialização da saúde no Brasil. Campinas: Saberes Ed., 2014. p. 83-84.
} 


\section{Os dados relativos ao consumo do hormônio do crescimento na Secretaria de Saúde Pública do Estado do Pará no período de 2009 a 2013}

\subsection{Métodos}

O estudo é uma pesquisa documental com abordagem descritiva de dados, obtidos na Central de Apoio Logístico do Departamento de Assistência Farmacêutica da Secretaria de Saúde Pública do Estado do Pará (CALOG/DEAF/SESPA) a partir da base de dados do Sistema Integrado de Materiais e Serviços (SIMAS), sistema gerencial destinado a todos os órgãos da Administração Pública que possuem recursos provenientes de tesouro Estadual e de informações registradas em planilhas e arquivos digitais do DEAF/SESPA ${ }^{53}$.

Foram avaliadas as informações que compreendem o período de janeiro de 2009 a dezembro de 2013, e a unidade de análise foi a aquisição do medicamento somatropina pela SESPA. Os itens pesquisados no estudo foram a apresentação de somatropina adquirida pelo órgão público, a origem da aquisição, a quantidade adquirida e o valor unitário do medicamento adquirido.

Inicialmente, foram identificados os códigos das apresentações de somatropina de 4 UI e somatropina de 12 UI cadastrados na base de dados do SIMAS, a partir dos quais foram coletados os demais itens definidos na pesquisa.

A quantidade adquirida durante o período de 2009 a 2013 foi retirada do relatório de pedidos de realização de despesas (PRD) gerados pela SESPA, com recebimento confirmado com a entrada da nota fiscal emitida pelo fornecedor do medicamento na base de dados do SIMAS.

O valor da somatropina adquirida foi coletado a partir da descrição do valor unitário constante no $\mathrm{PRD}$, que corresponde ao valor de cada frasco-ampola adquirido.

Quando, no período do ano em análise, houve variação do valor unitário nas aquisições realizadas, foi extraída a média dos valores apurados para efeito de cálculo do valor unitário do medicamento e do valor da UI (unidade internacional).

A origem da demanda foi identificada, após a análise documental em arquivos digitalizados do DEAF/SESPA, a partir da informação do número do processo ao qual cada aquisição correspondeu.

Três origens diversas foram localizadas: a aquisição destinada ao atendimento do CEAF e originada na DEAF/SESPA; as demandas administrativas originadas pela Assessoria Especial da SESPA; e as demandas judiciais iniciadas no Núcleo de Demanda Jurídica da SESPA.

\footnotetext{
${ }^{53}$ Os dados foram coletados com autorização do Departamento Estadual de Assistência Farmacêutica do Estado do Pará (DEAF/SESPA), por intermédio do processo 2015/60010, protocolado em 11 de fevereiro de 2015 (Anexo).
} 
A digitalização dos documentos no DEAF/SESPA somente começou em 2011, portanto não foi possível identificar com precisão, nos períodos de 2009 a 2010, se as demandas externas ao CEAF eram de origem administrativa ou judiciais. Dessa forma, optou-se por denominar essas origens como demandas externas ao CEAF.

Para identificar o período em que a somatropina de 12 UI esteve indisponível no estoque da CALOG/DEAF/SESPA para atender a demanda das Unidades de Dispensação do Estado e que motivou a ACP em comento, foi avaliada a ficha de prateleira - instrumento utilizado para registrar, por ordem cronológica, as informações correspondentes ao fluxo de entradas e saídas do medicamento.

\subsection{Resultados}

O valor total gasto com a aquisição do medicamento no período de janeiro de 2009 a dezembro de 2013 foi de $\mathrm{R} \$ 27.772 .856,80$ (Tabela 1 ), sendo $\mathrm{R} \$ 26.256 .864,30$ para atendimento do CEAF (Tabela 2) e R\$1.515.992,50 para o atendimento da demanda externa ao CEAF (Tabela 3).

Tabela 1. Valor gasto com a aquisição da somatropina de 4 UI e 12 UI, na SESPA, entre 2009 e 2013.

\begin{tabular}{ll}
\hline Ano & Valor $(\mathrm{R} \$)$ \\
\hline 2009 & $4.441 .290,00$ \\
2010 & $5.512 .925,80$ \\
2011 & $7.186 .522,00$ \\
2012 & $3.574 .215,00$ \\
2013 & $7.057 .904,00$ \\
Total & $27.772 .856,80$ \\
\hline
\end{tabular}

Fontes: SIMAS - CALOG/DEAF/SESPA. Elaboração: Autoras.

Tabela 2. Aquisição e custo da somatropina para atendimento do CEAF, entre 2009 e 2013, na SESPA, por apresentação.

\begin{tabular}{lcccc}
\hline \multirow{2}{*}{ ANO } & \multicolumn{2}{c}{ Somatropina 4 UI } & \multicolumn{2}{c}{ Somatropina 12 UI } \\
\cline { 2 - 5 } & $\begin{array}{c}\text { Quantidade } \\
\text { (frasco-ampola) }\end{array}$ & Valor (R\$) & $\begin{array}{c}\text { Quantidade } \\
\text { (frasco-ampola) }\end{array}$ & Valor (R\$) \\
\hline 2009 & 30.000 & $510.000,00$ & 24.975 & $3.927 .690,00$ \\
2010 & 28.000 & $455.000,00$ & 31.230 & $4.993 .677,00$ \\
2011 & 56.000 & $1.232 .000,00$ & 36.427 & $5.824 .677,30$ \\
2012 & 0 & 0,00 & 17.000 & $2.753 .820,00$ \\
2013 & 0 & 0,00 & 40.000 & $6.560 .000,00$ \\
Total & & $2.197 .000,00$ & & $24.059 .864,30$ \\
\hline
\end{tabular}

Fontes: Arquivo CALOG/DEAF/SESPA. Elaboração: Autoras. 
Os dados apresentados na Tabela 2 demostram que, a partir do ano de 2012, houve mudança no padrão de aquisição da somatropina na SESPA para o atendimento do CEAF, momento em que não se registrou a aquisição de somatropina de 4 UI, permanecendo apenas a aquisição de somatropina de 12 UI nos anos de 2012 e 2013.

A Tabela 3 demostra que, no ano de 2009, o quantitativo de somatropina adquirida para atender as demandas externas ao CEAF foi de apenas 90 frasco-ampolas. Fica evidente o crescimento, a cada ano, da aquisição do fármaco para atender demandas externas ao CEAF.

A aquisição de somatropina de 4 UI cresceu em 1.365,56 \% no período de 2009 a 2011, último ano em que foi adquirida. Já a aquisição da somatropina de 12 UI, iniciada no ano de 2010 , chegou a crescer $888,93 \%$ no período de 2010 a 2013.

A Tabela 4 demonstra que o frasco-ampola da somatropina de 12 UI apresentou maior custo em todas as aquisições se comparada à aquisição do frasco-ampola da somatropina de 4 UI. Para avaliar o valor de aquisição da somatropina de 4 UI e 12 UI, foi considerada a unidade de concentração do fármaco, ou seja, a UI.

No ano de 2009 o valor da UI por frasco-ampola de somatropina de 12 UI adquirida foi $84,8 \%$ maior que o valor da UI por frasco-ampola da somatropina de 4 UI, diferença que aumentou em 2011, último ano de aquisição da apresentação de 4 UI - quando o valor da UI por frasco-ampola de somatropina de 12 UI adquirida foi $140,9 \%$ maior que o valor da UI por frasco-ampola da somatropina de 4 UI.

Tabela 3. Aquisição e custo da somatropina para atendimento de demandas externas, entre 2009 e 2013, na SESPA, por apresentação.

\begin{tabular}{lcccc}
\hline \multirow{2}{*}{ ANO } & \multicolumn{2}{c}{ Somatropina 4 UI } & \multicolumn{2}{c}{ Somatropina 12 UI } \\
\cline { 2 - 5 } & $\begin{array}{c}\text { Quantidade } \\
\text { (frasco-ampola) }\end{array}$ & Valor (R\$) & $\begin{array}{c}\text { Quantidade } \\
\text { (frasco-ampola) }\end{array}$ & Valor (R\$) \\
\hline 2009 & 90 & $3.600,00$ & 0 & 0,00 \\
2010 & 301 & $7.950,00$ & 307 & $56.298,30$ \\
2011 & 1319 & $29.018,00$ & 628 & $100.826,70$ \\
2012 & 0 & 0,00 & 5050 & $820.395,00$ \\
2013 & 0 & 0,00 & 3036 & $497.904,00$ \\
Total & & $40.568,00$ & & $1.475 .424,00$ \\
\hline
\end{tabular}

Fontes: Arquivo CALOG/DEAF/SESPA. Elaboração: Autoras. 
Verbicaro L. P., Santos A. C. V.

Tabela 4. Valor de aquisição da somatropina, entre 2009 e 2013, na SESPA, por apresentação.

\begin{tabular}{lcccc}
\hline \multirow{2}{*}{ ANO } & \multicolumn{2}{c}{ Somatropina 4 UI (frasco-ampola) } & \multicolumn{2}{c}{ Somatropina 12 UI } \\
\cline { 2 - 5 } & Valor Unitário (R\$) & Valor por UI (R\$) & Valor Unitário (R\$) & Valor por UI (R\$) \\
\hline 2009 & 28,50 & 7,12 & 157,95 & 13,16 \\
2010 & 24,62 & 6,15 & 159,90 & 13,25 \\
2011 & 22,00 & 5,50 & 159,90 & 13,25 \\
2012 & - & - & 161,87 & 13,48 \\
2013 & - & - & 164,00 & 13,67 \\
\hline
\end{tabular}

Fontes: SIMAS - CALOG/DEAF/SESPA. Elaboração: Autoras.

\subsection{Discussão}

Os dados obtidos demonstram que a somatropina demandou valores elevados de recursos públicos, no período que compreendeu os anos de 2009 a 2013, quando foram investidos $\mathrm{R} \$ 27.772 .856,80$ para atendimento das demandas geradas no âmbito do Estado do Pará.

No contexto do CEAF, a mudança no padrão de aquisição da somatropina pela SESPA ocorreu a partir do ano de 2012, quando a apresentação de 4 UI não foi adquirida, permanecendo apenas a aquisição da apresentação de 12 UI.

Dos dados coletados na ficha de prateleira do medicamento somatropina de 12 UI, onde são registradas as entradas e saídas do medicamento no âmbito da CALOG/DEAF/SESPA, observou-se que no ano de 2011 houve longos períodos de desabastecimento no intervalo entre os meses de março de 2011 e junho de 2011. Nos meses subsequentes, embora constasse registro de entradas, o quantitativo recebido não atendia a demanda e em determinados períodos, embora mais curtos, ainda era possível observar o desabastecimento. Somente a partir de meados de outubro de 2011 deixa de ocorrer o desabastecimento com a normalização do estoque de forma contínua ${ }^{54}$.

A Tabela 2 demostra que no ano de 2011 houve um aumento considerável na aquisição de somatropina de 4 UI. Os dados coletados na pesquisa permitem afirmar que a aquisição dos 56.000 frascos-ampolas de somatropina de 4 UI no ano de 2011 ocorreu em setembro daquele ano, após a interposição da ACP; portanto, poder-se-ia inferir que o fato tenha ocorrido a fim de satisfazer a demanda não atendida de pacientes de somatropina de 12 UI, haja vista ser possível o ajuste de dose entre as duas apresentações.

A somatropina de 4 UI, adquirida nessa ocasião, foi de uma marca comercial diferente da comercializada anteriormente e, segundo informação da Coordenação

\footnotetext{
${ }^{54} \mathrm{Em}$ informações apreendidas nas publicações referentes ao processo disponível no endereço eletrônico do Tribunal de Justiça do Estado do Pará, a interrupção do fornecimento se deu por falta de matéria-prima para a fabricação do medicamento pelo laboratório.
} 
do Programa do Componente Especializado, houve vários relatos de dor no momento da aplicação, reação adversa descrita na bula do medicamento como reação incomum $(>1 / 1.000 \text { e } 0,1 \% \text { e }<1 \%)^{55}$, o que estaria provocando a rejeição dos pacientes à referida marca.

Importante ressaltar que no mesmo período foi deferido o pedido liminar em sede da ACP em comento que determinou o fornecimento do medicamento Hormotrop $p^{\circledR}$ - Somatropina de 12 UI a todas as crianças e adolescentes que apresentassem a deficiência do hormônio de crescimento como já descrito em capítulo específico.

A Tabela 2 evidencia que no ano de 2012 não há registro de aquisição da somatropina de $4 \mathrm{UI}$, permanecendo apenas a aquisição da somatropina de $12 \mathrm{UI}$ - que, por sua vez, apresenta queda acentuada quando comparada aos anos anteriores. A referida diminuição da aquisição de somatropina de 12 UI em 2012 pode ser justificada pela necessidade de consumo do quantitativo das duas apresentações adquiridas no ano anterior.

O desabastecimento da somatropina de $12 \mathrm{UI}$, ocorrido em períodos do ano de 2011, bem como a necessidade de atender a sua demanda reprimida - dando também cumprimento à determinação judicial decorrente da ACP e a rejeição dos pacientes à apresentação da somatropina de 4 UI disponível à época ${ }^{56}$ - promoveram $^{2}$ um desequilíbrio no processo de aquisição das duas apresentações do medicamento.

Dessa forma, no ano de 2013 não houve aquisição da somatropina de 4 UI, permanecendo apenas a aquisição da somatropina de 12 UI. A permanência da mudança do padrão de aquisição da somatropina, conforme referência supra e análise dos dados, decorreu de uma sucessão de acontecimentos, dentre eles o deferimento da decisão liminar que obrigou o fornecimento do Hormotrop ${ }^{\circledR}$ - Somatropina de12 UI.

A Tabela 3 demostra que as demandas externas ao CEAF iniciam-se em 2009 e que o aumento aconteceu de forma desproporcional de um ano para outro. Como já descrito no método, não foi possível identificar, nos anos de 2009 e 2010, o percentual de demandas administrativas e judiciais no universo das demandas externas ao CEAF. Os dados coletados no período de 2011 a 2013 permitem afirmar que as demandas judiciais representaram a maior parte das demandas externas ao CEAF, o que coincide com o aumento das demandas judiciais em todo o país, como descrito no desenvolvimento do trabalho. Os referidos dados não foram descritos nos resultados por não representarem a totalidade do período pesquisado.

Sobre os dados das demandas externas ao CEAF, representadas na Tabela 2, é importante destacar que se referem a pleitos de pacientes que, na maioria das vezes,

\footnotetext{
${ }^{55}{ }^{2}$ UTROPIN ${ }^{\circledR}$ (somatropina). Disponível em: <http://www.anvisa.gov.br/datavisa/fila_bula/frmVisualizarBula. asp?pNuTransacao $=10461952014 \&$ pldAnexo $=2320007>$.

${ }^{56}$ Importante registrar que o relato de reações adversas de forma isolada não tem, de per si, o condão de determinar a mudança no padrão de aquisição observada, haja vista não ser a única marca de somatropina de $4 \mathrm{UI}$ existente no mercado.
} 
não se enquadraram nas políticas públicas disponíveis no SUS e, portanto, buscaram vias alternativas de acesso, sejam judiciais sejam administrativas. Existem situações em que o paciente já busca o acesso pela via alternativa, mesmo existindo uma política pública que poderia atendê-lo pelas portas de acesso definidas na legislação do SUS, mas que é desconhecida pelo usuário e pela maioria dos operadores do direito nos casos de demandas judiciais.

A Tabela 4 demonstra que o custo de cada UI adquirida foi maior nas aquisições das apresentações de somatropina de 12 UI, chegando a uma diferença de $140,9 \%$ no ano de 2011 , de onde se conclui que adquirir exclusivamente a apresentação de 12 UI para atender a demanda do CEAF e as demandas externas ao CEAF importou na aquisição da apresentação mais dispendiosa para a gestão pública, no período pesquisado.

É inegável a legitimidade do interesse daqueles que recorrem aos tribunais, como no caso apresentado em que houve interrupção no abastecimento do medicamento definido em uma política pública vigente. Mas os dados demonstram a necessidade da aplicação de parâmetros técnicos que levem em consideração critérios sanitários da legislação vigente na condução de ações judiciais envolvendo saúde.

A realização do direito à saúde pelo Estado - assim como dos demais direitos sociais - dá-se por meio de políticas públicas, cuja elaboração e implementação dependem, para seu êxito, do emprego de conhecimentos específicos ${ }^{57}$.

Nesse sentido, o CNJ vem atuando para reduzir as consequências do excesso de ações judiciais na área da saúde, desde a aprovação da Recomendação n. 31/2010 58 , que traça diretrizes para os magistrados quanto às demandas que envolvem a assistência à saúde e recomenda aos tribunais a adoção de medidas - como a criação de Núcleos de Apoio Técnico, compostos por profissionais da área da saúde, assistentes sociais, gestores das secretarias estaduais e municipais de saúde - a fim de fornecer ao juiz informações necessárias que possam auxiliá-lo na análise do pedido liminar, promovendo assim uma integração entre os atores envolvidos na questão na busca da melhor decisão. Outra medida adotada pelo órgão foi a edição de enunciados que possam orientar os operadores do direito e profissionais da saúde quanto a procedimentos a serem adotados com o intuito de evitar a judicialização de demandas de saúde.

Há mecanismos extrajudiciais que visam a solucionar as demandas que envolvem o assistido e o SUS. No Estado do Pará, foi instituído o Comitê Interinstitucional de Resolução Administrativa de Demandas de Saúde (CIRADS) por meio de Acordo de Cooperação Técnica n. 004/2014, em que o Tribunal de

\footnotetext{
${ }^{57}$ SARMENTO, Daniel; TELLES, Cristina. op. cit., p. 125.

${ }^{58}$ CONSELHO NACIONAL DE JUSTIÇA. Recomendação n. 31, de 30 de março de 2010, cit.
} 
Justiça do Estado do Pará, a Procuradoria Geral do Estado do Pará, a Procuradoria Geral da República no Estado do Pará, a Defensoria Pública da União no Estado do Pará, a Defensoria Pública do Estado do Pará, a Advocacia Geral da União no Estado do Pará, o Ministério Público do Estado do Pará, a Secretaria Municipal de Assuntos Jurídicos do Município de Belém, a Secretaria de Estado de Saúde Pública do Pará e a Secretaria Municipal de Saúde do Município de Belém atuarão em parceria na análise de casos concretos a fim de identificar as causas do problema e encaminhar soluções.

\section{Considerações Finais}

O ponto de partida para a pesquisa foi a análise da medida liminar proferida nos autos da ACP 21681-17.2011.8.14.0301, que determinou à SESPA que fornecesse o medicamento Hormotrop ${ }^{\circledR}$ - Somatropina 12 UI para todas as crianças e adolescentes com deficiência na produção de hormônio do crescimento. $\mathrm{O}$ acesso aos dados de aquisição do medicamento do período de 2009 a 2013, no âmbito da SESPA, permitiu avaliar a mudança do padrão de aquisição da somatropina e como a decisão liminar influenciou essa mudança.

O estudo propôs-se, com base no caso concreto, a refletir sobre a necessidade de definição de parâmetros técnicos para subsidiar a análise das ações nos casos de demandas por medicamentos e serviços para saúde, questão fundamental para a manutenção de um sistema baseado na premissa da universalidade e destinado a aproximadamente 202 milhões de brasileiros.

Conforme demonstrado, a decisão da medida liminar nos autos da ACP em comento influenciou o padrão da aquisição, ao determinar o fornecimento da somatropina de 12 UI - apresentação mais dispendiosa segundo os dados coletados no período da pesquisa.

Reconhece-se que é inegável a legitimidade do interesse daqueles que recorrem aos tribunais, como no caso apresentado em que houve interrupção no abastecimento do medicamento definido em uma política pública vigente. No entanto, os dados demonstram a necessidade da aplicação de parâmetros técnicos que levem em consideração critérios sanitários da legislação vigente na condução de ações judiciais envolvendo saúde, para uma melhor otimização e eficiência nos gastos públicos e na efetivação dos direitos sociais.

Após a promulgação da $\mathrm{CF} / 88$, houve uma explosão crescente de ações judiciais para acesso ao SUS, fenômeno que apresenta consequências positivas e negativas à democracia brasileira: ao mesmo tempo em que permite uma via de acesso dos cidadãos às instâncias de poder, garantindo efetividade aos direitos sociais, propicia também a desestruturação da política de medicamentos e compromete o orçamento dos gestores em todos os níveis federativos. 
A apropriação teórica do tema da judicialização leva à percepção de que uma das condições para a sua existência no Brasil é a grande diferença entre a afirmação de direitos e as efetivas práticas de saúde ${ }^{59}$.

Em caráter conclusivo, entende-se que a participação cívica visa a buscar o equilíbrio como a melhor saída para os dilemas apresentados por esse fenômeno. Tal equilíbrio depende de um consenso e, para alcançá-lo, a discussão deve perpassar pelos magistrados, operadores do direito, gestores, pacientes, indústria farmacêutica e profissionais de saúde, de forma a se evitar que a excessiva judicialização da saúde promova a desigualdade e a fragilidade das políticas públicas de saúde, em evidente prejuízo à garantia dos direitos sociais à coletividade.

\section{Referências}

AGÊNCIA NACIONAL DE VIGILÂNCIA SANITÁRIA. Câmara de Regulação - CMED Secretaria Executiva. Disponível em: <http://portal.anvisa.gov.br/documents/374947/2829072/ LISTA_CONFORMIDADE_GOV_2016-05-23.pdf/c9eefbc3-28b1-485d-95bd66fb6b65c21e>.

BLIACHERIENE, Ana Carla et al. Acesso aos bens de saúde do SUS pela via Judicial. Interesse Público, Belo Horizonte, n. 70, p. 97-122, nov./dez. 2011.

BLIACHERIENE, Ana Carla; RUBIN, Thiago; SANTOS, José Sebastião dos. Delimitação do sentido normativo dos princípios doutrinários do direito à saúde como parâmetro mitigador da judicialização das políticas públicas de saúde. In: SANTOS, Lenir; TERRAZAS, Fernanda (Org.). Judicialização da saúde no Brasil. Campinas: Saberes Ed., 2014. p. 333-365.

BRASIL. Conselho Nacional de Secretários da Saúde. Direito à saúde: coleção para entender a gestão do SUS. Brasília: Conass, 2015.

SUPREMO TRIBUNAL FEDERAL. Despacho Convocatório - STF. Disponível em: $<$ http://www.stf.jus.br/arquivo/cms/processoAudienciaPublicaSaude/anexo/Despacho_ Convocatorio.pdf $>$.

CENTRO COLABORADOR DO SUS: AVALIAÇÃO DE TECNOLOGIAS E EXCELÊNCIA EM SAÚDE (CATES). Universidade Federal de Minas Gerais. Avaliação comparativa das apresentações de Somatropina disponibilizadas pelo SUS e demais comercializadas. Belo Horizonte, 2015. 57 p. Disponível em: <http://www.ccates.org.br/content/_pdf/ PUB_1426103238.pdf>. Acesso em: 25 mar. 2016.

EUTROPIN $^{\circledR}$ (somatropina). Disponível em: <http://www.anvisa.gov.br/datavisa/fila_bula/ frmVisualizarBula.asp?pNuTransacao=10461952014\&pIdAnexo=2320007 $>$.

${ }^{59}$ MACHADO, Felipe Rangel de Souza; DAIN, Sulamis. op. cit., p. 486. 
FIGUEIREDO Mariana Filchtiner; SARLET, Ingo Wolfgang. Notas sobre o direito fundamental à proteção e promoção da saúde na ordem jurídico-constitucional brasileira. In: ASENSI, Felipe Dutra; PINHEIRO, Roseni (Orgs.). Direito sanitário. Rio de Janeiro: Elsevier, 2012. p. 27-69.

FLEURY, Sonia; FARIA, Mariana. A Judicialização como ameaça e salvaguarda do SUS. In: SANTOS, Lenir; TERRAZAS, Fernanda (Org.). Judicialização da saúde no Brasil.Campinas: Saberes Ed., 2014. p. 101-123.

FREITAS, Cristina Leitão Teixeira. Judicialização da saúde, solidariedade e ressarcimento: destaques da posição dos Estados frente a polarização de entendimentos. In: SANTOS, Lenir; TERRAZAS, Fernanda (Org.). Judicialização da saúde no Brasil. Campinas: Saberes Ed., 2014. p. 59-96.

GARAPON, Antoine. O juiz e a democracia: o guardião das promessas. Rio de Janeiro: Renavan, 2001.

INSTITUTO BRASILEIRO DE GEOGRAFIA E ESTATÍSTICA. Antropometria e estado nutricional de crianças, adolescentes e adultos no Brasil: POF 2008-2009. Brasil, 2010. 42 p. Disponível em: <http://www.ibge.gov.br/home/estatistica/populacao/condicaodevida/ pof/2008_2009_encaa/pof_20082009_encaa.pdf>. Acesso em: 14 mar. 2015.

LONGUI, Carlos Alberto. Uso de GH em Pacientes com Baixa Estatura Idiopática. Arq. Bras. Endocrinol Metab, São Paulo, v. 5, n. 52, p.750-756, dez. 2008.

MACHADO, Felipe Rangel de Souza; DAIN, Sulamis. Direito e saúde: contribuições para o estudo da judicialização. In: ASENSI, Felipe Dutra; PINHEIRO, Roseni (Orgs.). Direito sanitário. Rio de Janeiro: Elsevier, 2012. p. 463-489.

MATFIN, Glenn; PORTH, Carol Mattson. Fisiopatologia. Tradução de: Pathophysiology: concepts of altered health states. $8^{\text {th }}$ ed. Rio de Janeiro: Guanabara Koogan, 2010. 2v.

MILAGRES, Marcelo de Oliveira. Saúde: direito, dever ou valor? Revista CEJ, Brasília, n. 50, p. 25-29, jul./set. 2010. Disponível em: <www.cjf.jus.br/ojs2/index.php/revcej/article/ viewArticle/1392>.

MINISTÉRIO DA SAÚDE. Curvas de Crescimento da Organização Mundial da Saúde - OMS. Disponível em: <http://dab.saude.gov.br/portaldab/ape_vigilancia_ alimentar.php?conteudo=curvas_de_crescimento $>$.

OLIVEIRA, Juliana Melo Corrêa Albuquerque; VERBICARO, Loiane Prado. A saúde pública jurisdicionalizada no Estado do Pará: Centro Universitário do Estado do Pará, Belém, 2013.

SARMENTO, Daniel; TELLES, Cristina. Judicialização da saúde e responsabilidade federativa: solidariedade ou subsidiariedade? In: ASENSI, Felipe Dutra; PINHEIRO, Roseni (Orgs.). Direito Sanitário. Rio de Janeiro: Elsevier, 2012. p. 117-129.

SCLIAR, Moacyr. História do conceito de saúde. Disponível em:<http://www.scielo.br/pdf/ physis/v17n1/v17n1a03.pdf>. Acesso em: 03 fev. 2015. 
SHOLL-FRANCO, Alfred et al. A influência da baixa estatura sobre as representações psicossociais e a utilização do hormônio do crescimento. Ciências e Cognição, v. 2, 2004, p. 50-60, 2004. Disponível em: <http://cienciasecognição.org/revista/index.php/cec/aticle/ view/30/23>. Acesso em: 10 abr. 2015.

SILVERTHORN, Dee Unglaub. Fisiologia humana: uma abordagem integrada. 5. ed. Porto Alegre: Artmed, 2010.

SOARES, J. C. R. D. S; DEPRÁ, A. S. Ligações Perigosas: indústria farmacêutica, associações de pacientes e as batalhas judiciais por acesso a medicamentos. Physis: Revista de Saúde Coletiva, Rio de Janeiro, v. 22, p. 311-329, 2012. Disponível em: <www.scielo.br/scielo.php?script=sci_artt ext\&pid=S0103-73312012000100017 > . http://dx.doi.org/10.1590/S0103-73312012000100017.

TATE, Neal; VALLINDER, T. The global expansion of judicial power. New York: New York University Press, 1995.

TERRAZAZ, Fernanda. Novos elementos no cenário da judicialização da saúde: análise das decisões dos tribunais superiores. In: SANTOS, Lenir; TERRAZAS, Fernanda (Org.). Judicialização da saúde no Brasil. Campinas: Saberes Ed., 2014.

VERBICARO, Loiane Prado. Um estudo sobre as condições facilitadoras da judicialização da política no Brasil. Revista Direito GV, v. 4, n. 8, jul./dez. 2008.

Loiane Prado Verbicaro - Doutora em Filosofia do Direito pela Universidade de Salamanca; mestre em Direitos Fundamentais e Relações Sociais pela Universidade Federal do Pará; mestre em Ciência Política pela Universidade Federal do Pará; graduanda em Filosofia pela Universidade Federal do Pará. Coordenadora e professora da Graduação e Vice-Coordenadora e professora do Programa de Mestrado em Direito do Centro Universitário do Estado do Pará. É líder do grupo de pesquisa CNPQ: Democracia, Poder Judiciário e Direitos Humanos. Belém/PA, Brasil.E-mail: loianeverbicaro@uol.com.br.

Andreza Casanova Vongrapp Santos - Mestranda em Direito pelo Centro Universitário do Pará; graduada em Farmácia e em Direito pelo Centro Universitário do Pará. Farmacêutica na Procuradoria Geral do Estado do Pará, no Subnúcleo de Direitos Sociais. Belém/PA, Brasil. E-mail: andreza@vongrapp.com.br. 


\title{
A judicialização do acesso ao hormônio do crescimento no Estado do Pará
}

\author{
GOVERNO DO ESTADO DO PARÁ \\ Secretaria Especial de Estado de Proteção e Desenvolvimento Social \\ Secretaria de Estado de Saúde Pública \\ Diretoria de Políticas de Atenção Integral à Saúde \\ Departamento Estadual de Assistência Farmacêutica
}

OF. № $037 / 2016$ - DEAF / DPAIS/ SESPA

Belém, 18 de março de 2016.

Assunto: Coleta de dados realizada no Departamento de Assistência Farmacêutica do Estado do Pará/SESPA

Prezada Senhora,

Venho através deste, autorizar o uso e manifestar ciência da coleta de dados realizada no Departamento de Assistência Farmacêutica do Estado do Pará/SESPA vinculada à pesquisa intitulada " Os efeitos da Ação Civil Pública nº 00216811720118140301 sobre o fornecimento do hormônio de crescimento na Secretaria de Saúde Pública do Estado do Pará e a necessidade de parâmetros para efetivação do direito à saúde", solicitada por Andreza Casanova Vongrapp Santos, cuja autorização foi expedida no Processo n 2015/60010.

Atenciosamente,

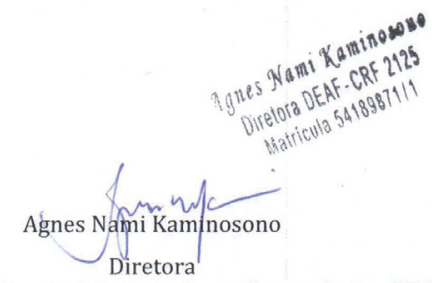

Departamento Estadual da Assistência Farmacêutica/SESPA

\section{À Prof ${ }^{\mathrm{a}}$ Drª Loiane da Ponte Souza Prado Verbicaro}

Coordenadora Adjunta do Curso de Direito do Centro Universitário do Estado do Pará CESUPA - Belém-Pa.

Rua dos Timbiras 1827 Ed. Alliance - Jurunas / CEP66017-000 Belém Pará - 40097450 deaf@sespa.pa.gov.br 